Article

\title{
Shear Stress and RBC-NOS Serine1177 Phosphorylation in Humans: A Dose Response
}

\author{
Jarod T. Horobin ${ }^{1,2, *(D)}$, Surendran Sabapathy ${ }^{1}$, Lennart Kuck ${ }^{1,2}$ and Michael J. Simmonds ${ }^{1,2}$ \\ 1 Menzies Health Institute Queensland, Griffith University, 4222 Gold Coast, Australia; \\ s.sabapathy@griffith.edu.au (S.S.); lennart.kuck@griffithuni.edu.au (L.K.); \\ m.simmonds@griffith.edu.au (M.J.S.) \\ 2 Biorheology Research Laboratory, Griffith University, 4222 Gold Coast, Australia \\ * Correspondence: jarod.horobin@live.com.au or j.horobin@griffith.edu.au
}

check for

updates

Citation: Horobin, J.T.; Sabapathy, S.; Kuck, L.; Simmonds, M.J. Shear Stress and RBC-NOS Serine1177

Phosphorylation in Humans: A Dose Response. Life 2021, 11, 36. https:// doi.org/10.3390/life11010036

Received: 14 December 2020

Accepted: 4 January 2021

Published: 8 January 2021

Publisher's Note: MDPI stays neutral with regard to jurisdictional clai$\mathrm{ms}$ in published maps and institutional affiliations.

Copyright: $\odot 2021$ by the authors. Licensee MDPI, Basel, Switzerland. This article is an open access article distributed under the terms and conditions of the Creative Commons Attribution (CC BY) license (https:// creativecommons.org/licenses/by/ $4.0 /)$.

\begin{abstract}
Red blood cells (RBC) express a nitric oxide synthase isoform (RBC-NOS) that appears dependent on shear stress for Serine1177 phosphorylation. Whether this protein is equally activated by varied shears in the physiological range is less described. Here, we explored RBC-NOS Serine1177 phosphorylation in response to shear stress levels reflective of in vivo conditions. Whole blood samples were exposed to specific magnitudes of shear stress $(0.5,1.5,4.5,13.5 \mathrm{~Pa})$ for discrete exposure times (1, 10, $30 \mathrm{~min})$. Thereafter, RBC-NOS Serine1177 phosphorylation was measured utilising immunofluorescence labelling. Shear stress exposure at $0.5,1.5$, and 13.5 Pa significantly increased RBC-NOS Serine1177 phosphorylation following $1 \mathrm{~min}(p<0.0001)$; exposure to $4.5 \mathrm{~Pa}$ had no effect after $1 \mathrm{~min}$. RBC-NOS Serine1177 phosphorylation was significantly increased following $10 \mathrm{~min}$ at each magnitude of shear stress $(0.5,1.5,13.5 \mathrm{~Pa}, p<0.0001 ; 4.5 \mathrm{~Pa}, p=0.0042)$. Shear stress exposure for 30 min significantly increased RBC-NOS Serine1177 phosphorylation at $0.5 \mathrm{~Pa}$ and 13.5 $\mathrm{Pa}(p<0.0001)$. We found that RBC-NOS phosphorylation via shear stress is non-linear and differs for a given magnitude and duration of exposure. This study provides a new understanding of the discrete relation between RBC-NOS and shear stress.
\end{abstract}

Keywords: nitric oxide synthase; erythrocytes; mechanotransduction; immunocytochemistry; mechanobiology; biorheology

\section{Introduction}

The components of the cardiovascular system (i.e., heart, vessels, and blood) are constantly exposed to flow-induced/-mediated shear stress that stimulates biochemical pathways. Indeed, one of the most important signalling molecules within the cardiovascular system, nitric oxide (NO), may be endogenously produced via shear stress. Nitric oxide is a key mediator of vascular homeostasis and exerts multiple protective functions due to its free radical nature, and the ability of nitrogen to assume a variety of oxidation states [1]. The vasculoprotective functions of $\mathrm{NO}$ include antioxidant effects and respiratory control [2] and is well recognised as an important regulator of vessel tone. Circulating $\mathrm{NO}$ is thought to be predominantly generated by the enzyme endothelial NO synthase (eNOS), which is expressed within the endothelial layer lining the vasculature: NO is generated when L-arginine binds within the oxygenase domain of NOS and is converted to L-citrulline [3,4]. Although eNOS is well known to be the primary source of NO for regulating vascular tone, the presence of an active eNOS isoform within red blood cells (RBC-NOS) may present an alternate source of NO generation within the vasculature. For patients with a damaged or impaired endothelium (e.g., atherosclerosis patients) [5], this alternative source of NO may be of particular importance for maintaining vessel tone.

Seminal work by Kleinbongard et al. [6] identified that RBC may endogenously produce NO via a local eNOS-like isoform (i.e., RBC-NOS) that shares several characteristics with eNOS. Nitric oxide derived from RBC-NOS may increase RBC deformability via direct 
S-nitrosylation of cytoskeletal proteins, $\alpha$ - and $\beta$-spectrin [7] or contribute to the vascular pool of bioavailable NO. Within the RBC, NO readily binds to deoxyHb which has a high affinity for membrane bound anion exchanger, Band-3, to form iron-nitrosyl- $\mathrm{Hb}$ [8]. Jia et al. [9] elucidated that as $\mathrm{RBC}$ move into regions of increased $\mathrm{PO}_{2}$ (e.g., pulmonary system), $\mathrm{NO}$ translocates to the cysteine $\beta 93$ residue to form $\mathrm{SNO}-\mathrm{Hb}$ [10]. As RBC traverses the arterial system and $\mathrm{PO}_{2}$ once again decreases, $\mathrm{NO}$ loses its binding affinity for the cysteine $\beta 93$ residue of $\mathrm{SNO}-\mathrm{Hb}$ and is exported out of the cell via Band-3 [11]. Alternatively, $\mathrm{NO}$ may also bind with $\mathrm{OxyHb}$ to form $\mathrm{MetHb}$ and nitrate, and can rapidly react with $\mathrm{O}_{2}$ to form nitrite [12-14]. The allosteric release of NO from $\mathrm{RBC}$ in the form of nitrite has also been suggested to be via Band-3, based on a decrease in plasma nitrite following inhibition of Band-3 [15]. As such, the significance of RBC-NOS should not be understated as highlighted by arguably one of the most common disorders affecting RBC and vascular function, sickle cell disease.

Patients with sickle cell disease present with a higher level of RBC-NOS phosphorylation and increased intracellular nitrite levels when compared to healthy patients [16]. This increased RBC-NOS phosphorylation potentially modulates RBC deformability of these rigid RBC [17]; however, the ability of RBC-NOS to contribute to vascular function via NO is impaired in sickle cell disease patients-possibly due to scavenging by free haemoglobin in plasma which is high in sickle cell disease patients [18]. Nevertheless, given that decreased NO bioavailability within the vasculature has been demonstrated to contribute to cardiovascular pathologies including hypertension, atherosclerosis and angiogenesisassociated disorders [19-21], and the ability of RBC-derived NO to potentially contribute to enhanced RBC deformability [7], platelet function [22], and vascular tone [23], elucidating the regulation of RBC-NOS within the vasculature may be of clinical importance.

The enzyme RBC-NOS demonstrates minimal activity for cells at stasis [24] and thus appears to be dependent upon shear stress for activation and production of NO in what appears to be a calcium-/calmodulin-dependent fashion [25,26]. Within endothelial cells, shear stress may activate protein kinase A, and protein kinase B (also known as Akt) pathways via mechanotransduction to increase inositol triphosphate production [27,28]. Subsequently, the regulatory carboxy-terminal tail of eNOS may be displaced via posttranslational phosphorylation of the key amino acid, Serine1177, thus relieving repression of NO synthesis by stimulating an influx of electrons within the reductase domain and increasing the $\mathrm{Ca}^{2+}$ sensitivity of eNOS [29]. It is not just shear stress that stimulates Akt phosphorylation but also growth factors including VEGF and insulin [30]. As such, it appears eNOS Serine1177 phosphorylation is integral for modulation of enzyme activity. Furthermore, the ability of eNOS Serine 1177 phosphorylation to increase $\mathrm{Ca}^{2+}$ sensitivity (also referred to as a calcium-independent pathway) in the modulation of NOS activity is of importance for patients receiving calcium channel inhibitors (e.g., patients with high blood pressure/atherosclerosis) where intracellular levels of calcium are likely to be decreased. Similarly, RBC-NOS has been reported by several groups to be phosphorylated at Serine1177 via the phosphoinositide-3 (PI3) kinase/Akt kinase pathway $[7,16,31]$ in response to shear stress and insulin [7]. These findings support research that has demonstrated RBC-NOS Serine1177 phosphorylation may improve RBC deformability, and that calcium channel blockers (which decrease intracellular calcium levels [32]) do not impede RBC deformability in hypertension patients [33]. The resolution of other important aspects of RBC-NOS, however, remains poor. Understanding the tolerance of RBC-NOS to shear stress, for example, would be useful to determine the potential (dys)regulation of this source of NO.

The physiological limits of shear stress within the cardiovascular system have been reported from 0.1 to $0.6 \mathrm{~Pa}$ across the venous network, while spanning 1 to $15 \mathrm{~Pa}$ within the arterial network [34,35]. Whilst previous studies have examined discrete magnitudes of shear stress on RBC-NOS phosphorylation [23,25], or examined RBC-NOS phosphorylation after being exposed to high-shear environments in either pulsatile or continuous flow [36], the ability to interrogate the effects of this species requires further understanding of 
the discrete relation between RBC-NOS Serine1177 phosphorylation and shear stress. Indeed, the relationship between RBC-NOS and shear stress has yet to be adequately characterised. The primary aim of the current study was to assess RBC-NOS Serine1177 phosphorylation across a physiologically relevant range of constant shear stresses: previous work suggests no difference between pulsatile and continuous shear stress. The secondary aim of the current study was to identify whether Serine1177 phosphorylation of RBC-NOS is dependent upon the bioavailability of L-arginine via inhibition with $\mathrm{N \omega}$-Nitro-L-arginine methyl ester hydrochloride (L-NAME) which competitively binds to the arginine binding site and thus inhibits NO production.

\section{Material and Methods}

\subsection{Subjects and Sampling}

Venous blood was collected from 10 healthy male donors only (age: $28 \pm 7$ years) given gender differences in haematological, hemorheological, and especially NO-related parameters [37], and anticoagulated with lithium heparin (BD Vacutainer ${ }^{\circledR} ; 158$ USP). Written and witnessed informed consent was provided by each participant and the use of blood was consistent with The Code of Ethics of the World Medical Association (Declaration of Helsinki). The experimental procedures were reviewed and approved by the Griffith University Human Research Ethics Committee (HREC GU Ref. 2016/712).

\subsection{Experimental Overview}

A subset of four blood samples were evaluated per subject in the present study which involved three phases. The first phase was measurement of whole blood viscosity to facilitate the calculation of individualised shear stress exposure protocols. The second phase was a "conditioning" period during which discrete blood samples were exposed to a specific magnitude of shear stress (i.e., $0.5,1.5,4.5$, and $13.5 \mathrm{~Pa}$ ) for $30 \mathrm{~min}$-the order of which was randomised to ensure no system bias in the data. During each "conditioning" periods, an aliquot of blood was aspirated from the shearing device following 1,10 , and $30 \mathrm{~min}$ to allow for the examination of exposure duration on the dependent variables; the process of ceasing shearing and collecting each sample took $<30 \mathrm{~s}$ in total. The third phase was fixation of blood samples immediately following the aspiration from the shearing device for preservation of RBC-NOS phosphorylation. The durations of exposure were chosen based on previous works that have investigated Serine1177 phosphorylation of eNOS, and mechanical changes to RBC following exposure to shear stress [25,27,38]. Basal levels of RBC-NOS phosphorylation were examined by using an aliquot of RBC that had not been previously sheared (i.e., control); these samples were collected and fixed in the same manner as the experimental data.

To evaluate the second Aim and provide further understanding of the key characteristics of RBC-NOS, a second study $(n=5)$ was conducted to assess the inhibitory effect of L-NAME on RBC-NOS phosphorylation. This sub-study involved the evaluation of four blood samples: (1) RBC exposed to a shear stress conditioning of $13.5 \mathrm{~Pa}$ for $10 \mathrm{~min}$; (2) RBC pre-incubated with $5 \mathrm{mM}$ L-NAME ( $5 \mathrm{mM}$; N5751, Sigma-Aldrich; St. Louis, MO, USA) for $1 \mathrm{~h}$ at room temperature and then exposed to a shear stress conditioning of $13.5 \mathrm{~Pa}$ for 10 min; (3) RBC with no prior exposure to shear stress; and (4) RBC pre-incubated with $5 \mathrm{mM}$ L-NAME for $1 \mathrm{~h}$ at room temperature with no prior exposure to shear stress.

\subsection{Exposure of Red Blood Cells to Shear Stress}

Viscosity ( $\eta$ ) of blood at native haematocrit was measured using a calibrated rotational cone-plate viscometer operated at $37^{\circ} \mathrm{C}(0.5 \mathrm{DVII}+$ with CPE40 spindle, Brookfield Engineering Labs; Middleboro, MA, USA). Thereafter, a fresh blood subset was loaded into the shearing system for the application of shear stress: the shearing system is principally employed for the measurement of RBC deformability from a low haematocrit sample of RBC suspended in a Newtonian viscous fluid. As whole blood samples were used, however, the measurement of deformability was not possible in this study. The shearing 
system (LORRCA MaxSis, Mechatronics; Zwaag, Hoorn, The Netherlands) consists of two concentric cylinders; the outer cylinder is temperature-regulated at $37^{\circ} \mathrm{C}$ and is rotated at discrete speeds to apply a shear rate to the fluid between the two cylinders. Thus, for the experimental protocol, the shear stress could be calculated given that the viscosity of blood was measured, and the shear rate $(\dot{\gamma})$ applied to the gap of the shearing system could be quantified. First, to calculate the shear rate required to apply the desired magnitude of shear stress for a known viscosity solution, the following equation described by Hardeman, Goedhart [39] was used:

$$
\dot{\gamma}=2 \times \frac{2 \pi}{60} \frac{r_{1} \times r_{2}}{r_{2}^{2}-r_{1}^{2}} \times N
$$

where $r_{1}$ and $r_{2}=$ radius of the inner and outer cylinder, respectively; $N=\mathrm{rev} / \mathrm{min}$ of the outer cylinder. The shear stress was then calculated using the equation:

$$
\tau=\eta \times \dot{\gamma}
$$

Subsequently, the rotational speed of the outer cylinder was set to obtain the pertinent shear rate for the discrete magnitude of shear stress to be applied. A fresh whole blood sample $(1200 \mu \mathrm{L})$ was utilised for each discrete assessment. The shearing system was then operated for $1 \mathrm{~min}$, after which shearing ceased for $10 \mathrm{~s}$ to allow for a small portion $(300 \mu \mathrm{L})$ of RBC suspension to be collected and immediately fixed with $4 \%$ paraformaldehyde. Application of shear was immediately recommenced, and the experimental protocol resumed for a further $9 \mathrm{~min}$ (i.e., $10 \mathrm{~min}$ of accumulated shear exposure). The shearing system was then paused a second time, to allow for another small portion $(300 \mu \mathrm{L})$ of RBC suspension to be collected and fixed. Application of shear recommenced once again and the experimental protocol resumed for a further $20 \mathrm{~min}$ (i.e., a total of $30 \mathrm{~min}$ shear exposure), before a final sample of RBC suspension was collected and fixed. All samples collected during this protocol were subsequently analysed for RBC-NOS Serine1177 phosphorylation. Note that for the secondary study (i.e., evaluation of L-NAME on RBC-NOS phosphorylation) all sheared samples were exposed to shear for 10 min continuously without ceasing after $1 \mathrm{~min}$.

\subsection{Red Blood Cell Nitric Oxide Synthase Serine1177 Phosphorylation}

The quantification of RBC-NOS Serine1177 phosphorylation was performed utilising an immunohistochemistry method adapted from published methods $[7,31,40]$ with a fluorescence detection method developed in-house. Suspensions of RBC collected during the shearing protocol were fixed with $4 \%$ paraformaldehyde in tris-buffered saline (TBS, $\mathrm{pH}$ 7.6) at a 1:1 ratio for $20 \mathrm{~min}$. Following fixation, samples were smeared onto a glass slide and a wax border was made around each blood smear to separate between the "test" area and negative control area using a Super PAP Pen (Catalogue No. 008899; ThermoFisher Scientific; Waltham, MA, USA). The blood smears were permeabilised with $0.1 \%$ trypsin and then incubated with a blocking buffer (3\% milk powder in $0.1 \mathrm{M}$ TBS with $0.001 \%$ Tween-20) for $30 \mathrm{~min}$ : this antigen retrieval step was performed to ensure the antigenicity of phosphorylated RBC-NOS was not reduced via formation of hydroxylmethylene bridges [41,42]. The test area of each slide was then incubated with anti-phospho eNOS (Ser1177; Merck Millipore; Burlington, MA, USA) in antibody diluent (TBS with $0.3 \%$ milk powder and $0.001 \%$ Tween-20, 1:200), while the control area was incubated with antibody diluent in the absence of the primary antibody. The increased dilution of milkpowder for the primary antibody incubation step was employed to minimise non-specific binding [43]. Afterward, the blood smears were incubated with a secondary blocking buffer ( $3 \%$ goat serum in $0.1 \mathrm{M}$ TBS) for $1 \mathrm{~h}$, followed by incubation with a goat anti-rabbit IgG secondary antibody (Vector Laboratories; Burlingame, CA, USA) in antibody diluent for $1 \mathrm{~h}$. A transition to goat serum (i.e., the species in which the secondary antibody was raised) was ventured to minimise non-specific binding and decrease background signal. The blood smears were then washed with TBS several times, dehydrated with a 
graded series of alcohols (70, 90, and 100\%), cleared with xylene (534056, Sigma-Aldrich; St. Louis, MO, USA), and then mounted with a purpose medium (Entellan ${ }^{\circledR}$ new; Merck Millipore; Burlington, MA, USA) and glass coverslip. Finally, smears were examined with a fluorescence objective (LUCPLFLN 40X/0.60) attached to an inverted microscope (IX73, Olympus Corp., Tokyo, Japan) coupled to a CMOS camera (optiMOS ${ }^{\mathrm{TM}}$ sCMOS; QImaging; Surrey, BC, Canada). Digital photos of the test area and negative control area were analysed using Image J software (National Institutes of Health, Bethesda, MD, USA), with the intensity of immunofluorescence representing the amount of RBC-NOS Serine1177 phosphorylation. The exposure time and gain settings for all images depicted in Figure 1 were set to be identical to minimise bias in interpretation of fluorescence intensity; however, this at times increased background "noise" (intensity of background fluorescence intensity) due to the large range of intensity between samples. The differences in these background intensities were accounted for, however, as described below in Data Analysis.
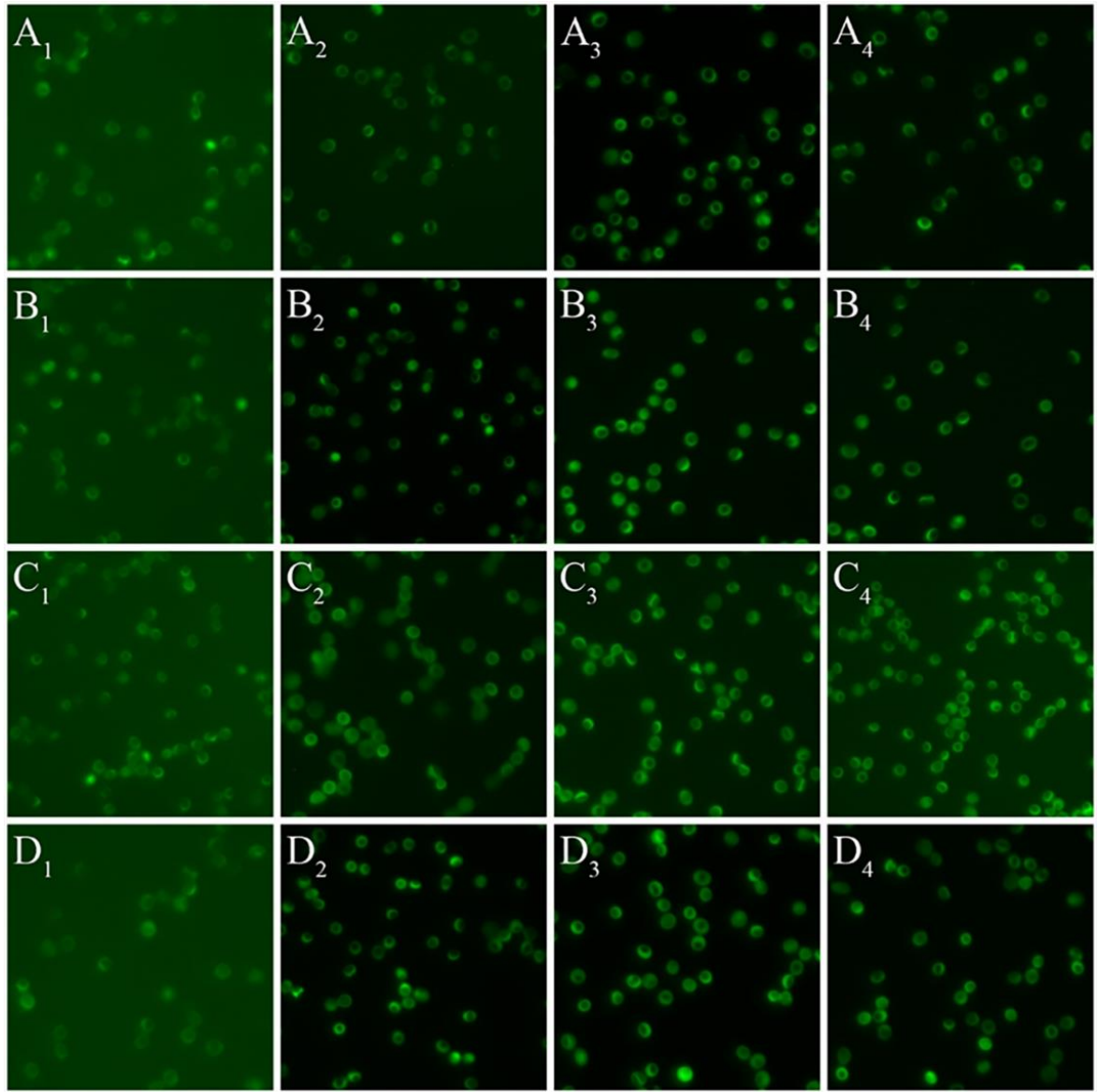

Figure 1. Fluorescence images of activated red blood cell-derived nitric oxide synthase following exposure to shear stress exposed to discrete magnitudes ((A): $0.5 \mathrm{~Pa},(\mathbf{B}): 1.5 \mathrm{~Pa},(\mathbf{C}): 4.5 \mathrm{~Pa},(\mathbf{D})$ : $13.5 \mathrm{~Pa}$ ) and durations (subscripts 1-4; representing $0,1,10$ and $30 \mathrm{~min}$, respectively).

\subsection{Data Analysis}

Initially, immunofluorescence intensity of both the test area and the control were quantified as the RBC grey value minus the mean background grey value, which was detected at a cell-free area of the slide; at least six cell-free regions were used to calculate the background value on each slide. Thereafter, the corrected total cell fluorescence (CTCF) for each cell was determined by subtraction of the immunofluorescence intensity of the control area from the immunofluorescence of the test area ( $\geq 50$ cells) as has been previously reported [16,44]. 


\subsection{Statistical Analysis}

The D'Agostino and Pearson test of normality was used to assess normality of the CTCF data. Subsequently, the Kruskal-Wallis test was used to determine whether significant differences in the mean CTCF existed. Dunn's multiple comparisons test was applied when examining multiple comparisons between durations of shear stress exposure for a given magnitude (Prism 7.04, GraphPad Software Inc.; San Diego, CA, USA). For assessment between samples pre-incubated with L-NAME and samples untreated, a two-way ANOVA was used to determine whether significant differences in the mean CTCF existed. The Bonferroni post hoc test was then employed when examining multiple comparisons (Prism 7.04, GraphPad Software Inc.; San Diego, CA, USA).

\section{Results}

\subsection{Whole Blood Viscosity}

Prior to accurate application of shear to samples, discrete blood viscosity was required to be measured to facilitate shear stress calculations; consequently, each sample's viscosity was determined across a dynamic range of shear rates. The shear stress was calculated using a relation between governed shear rate and measured viscosity. Thereafter, a matrix of shear stresses and respective shear rates was generated to achieve the desired shear stresses of $0.5,1.5,4.5$, and $13.5 \mathrm{~Pa}$. To obtain a shear stress magnitude of $0.5 \mathrm{~Pa}$, a shear rate of $122 \pm 17 \mathrm{~s}^{-1}$ was applied to whole blood samples. Likewise, a shear rate of $300 \pm 14$, $900 \pm 41$, and $2712 \pm 116 \mathrm{~s}^{-1}$ was applied to whole blood samples to obtain shear stress magnitudes of $1.5,4.5$, and $13.5 \mathrm{~Pa}$, respectively.

\subsection{Red Blood Cell Nitric Oxide Synthase Serine1177 Phosphorylation}

The mean RBC-NOS Serine1177 phosphorylation for blood samples exposed to shear stress stimulation at $0.5,1.5,4.5$, and $13.5 \mathrm{~Pa}$ for durations of 1,10 , and $30 \mathrm{~min}$ is presented in Figures 1 and 2. There was a significant increase in RBC-NOS Serine1177 phosphorylation following exposure to $0.5 \mathrm{~Pa}$ for $1 \mathrm{~min}(1294 \pm 33$ a.u.; $p<0.0001), 10 \mathrm{~min}$ $(1494 \pm 35$ a.u.; $p<0.0001)$, and $30 \mathrm{~min}(1184 \pm 24$ a.u.; $p<0.0001)$, when compared with baseline (934 \pm 33 a.u.; $0 \mathrm{~Pa}$ ). There was a significant decrease, however, in RBC-NOS Serine1177 phosphorylation following 30 min exposure to $0.5 \mathrm{~Pa}$ when compared to an exposure duration of $10 \mathrm{~min}(p=0.0004)$.

The mean Serine1177 phosphorylation of RBC-NOS was significantly increased following shear exposure to $1.5 \mathrm{~Pa}$ for $1 \mathrm{~min}(2173 \pm 57$ a.u.; $p<0.0001)$ and $10 \min (2063 \pm 39$ a.u.; $p<0.0001$ ), when compared to baseline. No significant difference was observed following exposure to $1.5 \mathrm{~Pa}$ for $30 \mathrm{~min}(764 \pm 20$ a.u.). Exposure to $1.5 \mathrm{~Pa}$ for $1 \mathrm{~min}$ induced the greatest response, as RBC-NOS Serine1177 phosphorylation significantly decreased when compared to an exposure duration of $30 \mathrm{~min}(p<0.0001)$. Moreover, RBC-NOS Serine1177 phosphorylation was significantly decreased following $30 \mathrm{~min}$ shear stress exposure at $1.5 \mathrm{~Pa}$ when compared to an exposure duration of $10 \mathrm{~min}(p<0.0001)$.

Exposure to a shear stress magnitude of $4.5 \mathrm{~Pa}$ for $1 \mathrm{~min}(952 \pm 25$ a.u.) did not induce a significant change in RBC-NOS Serine1177 phosphorylation when compared to baseline; however, there was a significant increase following $10 \min (1146 \pm 42$ a.u.; $p=0.0042)$. Indeed, the Serine1177 phosphorylation of RBC-NOS after $10 \mathrm{~min}$ exposure at $4.5 \mathrm{~Pa}$ was significantly greater when compared to an exposure duration of $1 \mathrm{~min}(p=0.0275)$. Following exposure to $4.5 \mathrm{~Pa}$ for $30 \mathrm{~min}$, there was no significant difference in RBC-NOS Serine1177 phosphorylation when compared to baseline (1351 \pm 116 a.u.). 


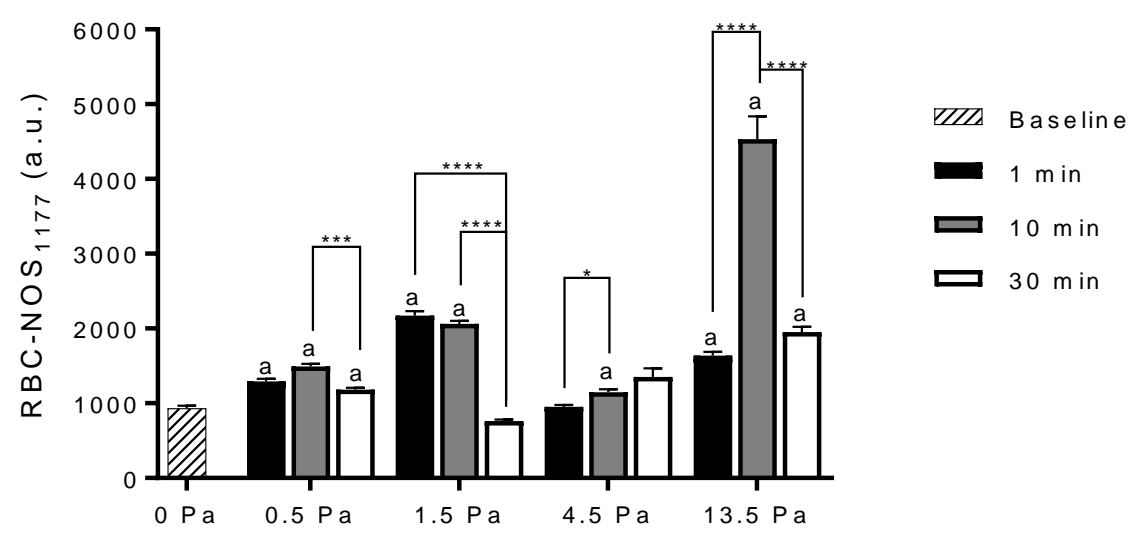

Figure 2. Corrected total cell fluorescence of Serine1177 phosphorylated RBC-NOS at baseline (0 Pa) and Figure 1. 10, and $30 \mathrm{~min}$, at shear stress magnitudes of 0.5, 1.5, 4.5, and 13.5 Pa. Data are presented as mean \pm SEM. ${ }^{*} p<0.05,{ }^{* *} p<0.001$ significant difference, ${ }^{* * *} p<0.0001$ significant difference. ${ }^{a}$ significant difference from RBC-NOS Serine1177 phosphorylation before shear stress. With $P$ values presented in text.

The mean RBC-NOS Serine1177 phosphorylation was significantly increased following exposure to $13.5 \mathrm{~Pa}$ for $1 \mathrm{~min}(1635 \pm 51$ a.u.; $p<0.0001), 10 \mathrm{~min}(4534 \pm 305$ a.u.; $p<0.0001)$ and $30 \mathrm{~min}(1953 \pm 70$ a.u.; $p<0.0001)$ when compared to baseline. Between exposures of 1 and $10 \mathrm{~min}$ there was a significant increase in the mean RBC-NOS Serine1177 phosphorylation $(p<0.0001)$. After peaking at $10 \mathrm{~min}$ of exposure to $13.5 \mathrm{~Pa}$, RBC-NOS Serine1177 phosphorylation significantly decreased after $30 \mathrm{~min}(p<0.0001)$, albeit remaining elevated compared with baseline.

The mean RBC-NOS phosphorylation for cells exposed to a shear stress magnitude of $13.5 \mathrm{~Pa}$ for $10 \mathrm{~min}$ (without a pause at $1 \mathrm{~min}$ as performed in the previous experiment), and cells that were unsheared (i.e., rest) in the absence (untreated) or presence of L-NAME are presented in Figure 3. There was a significant increase in RBC-NOS phosphorylation following exposure to $13.5 \mathrm{~Pa}$ for $10 \mathrm{~min}$ when compared to static non-sheared samples $(p<0.0001)$. Samples that were previously sheared and also those unsheared and preincubated with L-NAME had significantly decreased fluorescence when compared to respective Control samples $(p<0.0001)$. No significant difference in fluorescence of samples pre-incubated with L-NAME was observed between rest samples and sheared samples.

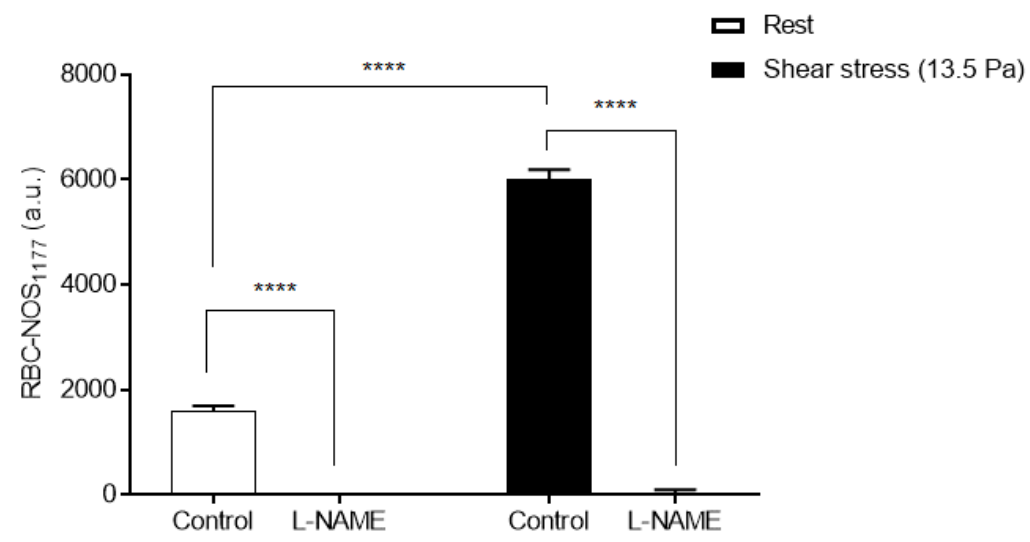

Figure 3. Corrected total cell fluorescence of Serine1177 phosphorylated RBC-NOS following exposure to shear stress of $13.5 \mathrm{~Pa}$ for $10 \mathrm{~min}$ and at rest in the absence (untreated) or presence of L-NAME. RBC-NOS Serine1177 phosphorylation before shear stress is presented as white bars, and samples exposed to $13.5 \mathrm{~Pa}$ for $10 \mathrm{~min}$ are presented as black bars. Data are presented as mean $\pm \mathrm{SEM}, n=5$. **** $p<0.0001$ significant difference. 


\section{Discussion}

The aim of the present study was to examine changes in RBC-NOS Serine1177 phosphorylation stimulated by discrete magnitudes and durations of shear stress exposure. The principal finding was that the stimulation of RBC-NOS via shear stress is dependent upon both shear stress magnitude and duration in a non-linear manner. Low shear (i.e., $0.5 \mathrm{~Pa}$ ) significantly increased RBC-NOS Serine 1177 phosphorylation following exposure at all durations when compared to baseline; however, the magnitude of RBC-NOS Serine1177 phosphorylation was significantly decreased at $30 \mathrm{~min}$ exposure when compared to $10 \mathrm{~min}$ exposure (Figure 2). Phosphorylation of RBC-NOS Serine1177 at $1.5 \mathrm{~Pa}$ was induced in a rapid fashion but declined rapidly with continued exposure (e.g., 30 min exposure was significantly decreased compared to $10 \mathrm{~min}$ exposure). A shear stress magnitude of $4.5 \mathrm{~Pa}$ induced the least amount of RBC-NOS Serine1177 phosphorylation: a significant difference in RBC-NOS Serine1177 phosphorylation was observed only following 10 min when compared to baseline. Finally, a significant increase in RBC-NOS Serine1177 phosphorylation was observed following high shear exposure (i.e., $13.5 \mathrm{~Pa}$ ) for all durations when compared to baseline with the greatest magnitude of RBC-NOS Serine1177 phosphorylation observed following $10 \mathrm{~min}$ exposure.

The phosphorylation of RBC-NOS was significantly increased following exposure to a shear stress magnitude of $0.5 \mathrm{~Pa}$ for all durations of exposure when compared to baseline; however, a significant decrease was identified after $30 \mathrm{~min}$ when compared to durations of $10 \mathrm{~min}$. These data suggest RBC-NOS reaches maximal phosphorylation relative to $0.5 \mathrm{~Pa}$ after $10 \mathrm{~min}$. To the best of our knowledge, no previous in vitro or in vivo studies have directly examined RBC-NOS or eNOS phosphorylation at $0.5 \mathrm{~Pa}$. However, Dimmeler et al. [45] previously observed via eNOS immunoprecipitation and phosphoamino acid analysis a significant increase in Akt phosphorylation following exposure to a shear stress magnitude of $5 \mathrm{dyn} / \mathrm{cm}^{2}$ (i.e., $0.5 \mathrm{~Pa}$ ), and determined Akt phosphorylation significantly increased eNOS phosphorylation. Dimmeler et al. [45] observed a maximal response in Akt phosphorylation following $1-2 \mathrm{~h}$ which suggests the time to maximal eNOS phosphorylation is likewise greater than the maximal response observed for RBCNOS in the current study. Indeed, an in silico study by Koo et al. [46] determined that the time to maximal eNOS phosphorylation following exposure to $0.5 \mathrm{~Pa}$ is approximately $30 \mathrm{~min}$. The current study indicates that RBC-NOS exposed to $0.5 \mathrm{~Pa}$ exhibits an ability to reach maximum enzymatic activation that is expedited when compared to eNOS. It is possible this difference is the result of substrate availability. As eNOS is membrane bound, Shin et al. [47] determined that endothelial cells are reliant on extracellular (i.e., plasma) bioavailability of L-arginine: circulating plasma concentration of L-arginine is approximately $50-100 \mu \mathrm{M}$. In contrast, RBC-NOS which is found within the intracellular and membrane compartments [6], may rapidly uptake $200 \mu \mathrm{M}$ L-arginine, in approximately 10 min [48] which stimulates NOS phosphorylation through the PI3 kinase/Akt kinase pathway $[49,50]$.

The present study demonstrates that exposure to shear stress at 1.5 Pa significantly increased RBC-NOS phosphorylation after $1 \mathrm{~min}$ and $10 \mathrm{~min}$. These data are congruent with the findings by Boo et al. [27] (observed via Immunoblotting), where eNOS activity, as indicated by Serine1177 phosphorylation, was stimulated via shear stress after $2 \mathrm{~min}$ at $1.5 \mathrm{~Pa}$. The present data and the data from Boo et al. [27] are not directly comparable, however, due to differences in detecting NOS phosphorylation. Continued exposure to a shear magnitude of $1.5 \mathrm{~Pa}$ in the present study saw a decline in RBC-NOS phosphorylation following 10, and $30 \mathrm{~min}$ when compared to RBC-NOS phosphorylation at $1 \mathrm{~min}$. No previous studies have directly investigated the effects of a shear stress exposure at $1.5 \mathrm{~Pa}$ on RBC-NOS phosphorylation; however, the decline in RBC-NOS phosphorylation following 1 min shear exposure at 1.5 Pa may be explained by negative feedback common to eNOS isotypes [51]. It has been previously demonstrated within endothelial cells that eNOS activity may be decreased via shear-mediated processes that produce secondary species, such as peroxynitrite, that may lead to oxidation of the eNOS enzyme $[52,53]$. It is well 
established that NO readily binds to superoxide to form the oxidant, peroxynitrite, and that peroxynitrite readily oxidises biomolecules, and may form nitrated adducts [54-56]. Given the significant increase in RBC-NOS phosphorylation following $1 \mathrm{~min}$, it is likely that intracellular NO bioavailability was increased at this time-point. Consequently, it is plausible that RBC-NOS activity (due to phosphorylation) may have been auto-regulated by the accumulation of intracellular NO to minimise oxidative stress induced by increased RBC-NOS enzymatic activity. Indeed, the prolonged shears in the present study may have led to an imbalance in normal redox state of the cells, that experience fluctuating but highly intermittent shears during their passage of the circulatory system.

The phosphorylation of RBC-NOS following exposure to $4.5 \mathrm{~Pa}$ was highly dependent upon exposure time; no changes were observed after 1 and $30 \mathrm{~min}$ of exposure, although was significantly increased after $10 \mathrm{~min}$ exposure. Although no previous studies have investigated the effects of a shear stress magnitude of $4.5 \mathrm{~Pa}$ on eNOS phosphorylation, these data are consistent with the emergent hypothesis that prolonged exposure to higher magnitudes of shear stress may lead to auto-regulation of RBC-NOS enzymatic activity via negative feedback induced by accumulated intracellular NO. A limitation of the present study, however, is that $\mathrm{NO}$ was not measured directly due to the methodology employed, thus no definitive conclusion can be made at this time.

The present study observed a significant increase in RBC-NOS phosphorylation following exposure to a shear stress magnitude of $13.5 \mathrm{~Pa}$ for all durations when compared to baseline. The shear stress magnitude of $13.5 \mathrm{~Pa}$ utilised in the present study represents the upper limits of shear stress observed within the circulatory system of healthy individuals [34]. It is plausible this is due to the functional requirements of RBC needing to maximally deform when traversing blood vessels, and the release of $\mathrm{NO}$ for propagation of microvascular control that may aid in effective oxygenation $[57,58]$. It is within the microcirculation that RBC are exposed to the upper limits of shear stress, as well as an oxygen gradient where $~ 50-65 \%$ of haemoglobin-bound oxygen is released to venous exchange [59-61]. Stamler et al. [10] proposed NO may be released from haemoglobin in areas with low partial pressure of oxygen to regulate local blood flow. However, oxygen demand and oxygen levels are often spatially heterogeneous in tissues and as such, upstream communication to the arteriole is required from the downstream capillaries for effective oxygenation [58]. Therefore, given the present results, it is plausible that microvascular control is not only a function of oxygenation state, nitric oxide-mediated vasodilation, and conducted responses propagated upstream along the vasculature, but also mechanotransduction. In other words, a critical threshold may exist above $4.5 \mathrm{~Pa}$ and/or equal to $13.5 \mathrm{~Pa}$ for the phosphorylation of RBC-NOS and subsequent production and release of RBC-derived NO for maintenance of vascular control. The exact mechanism for sustained activation of RBC-NOS at high shear was not investigated in this study; however, the sensitisation of RBC-NOS to calmodulin may be enhanced at high shear via crosstalk of associated proteins in a manner similar to eNOS [62-64], thus overcoming any auto-regulation of enzymatic phosphorylation. Nevertheless, limitations of the current study necessitate further research into the effects of shear stress on RBC-NOS protein-protein interactions.

In the present study, L-NAME completely removed the fluorescence signal of RBCNOS under static conditions (e.g., rest) and when exposed to $13.5 \mathrm{~Pa}$ of shear stress constant for $10 \mathrm{~min}$ (Figure 3). L-NAME competes with the substrate L-arginine for preferential binding at the arginine-binding site within the oxygenase domain of NOS to inhibit NOS activity [65]. Given that RBC-NOS Serine1177 phosphorylation occurs within the reductase domain, it was not clear whether L-NAME would affect RBC-NOS Serine1177 phosphorylation per se. Nevertheless, several studies have demonstrated that L-arginine plays a role in the phosphorylation and activation of the PI3 kinase/Akt kinase pathway $[49,50]$. Given the present findings, it is plausible that the specific NOS inhibitor, L-NAME, may also indirectly inhibit NOS phosphorylation via inhibition of upstream NOS regulatory proteins (e.g., PI3/Akt kinase), at least using the concentration employed in 
the present study. However, the measurement of PI3 kinase phosphorylation/Akt activity, and enzymatic productivity (i.e., NO concentration), was not employed in the current study, precluding definitive analysis of upstream pathways associated with RBC-NOS phosphorylation and RBC-NOS-derived NO production following shear exposure.

\section{Conclusions}

The current study investigated the effect of shear stress exposure on RBC-NOS Serine1177 phosphorylation within the physiological range and identified a non-linear response. The time required to reach maximal RBC-NOS Serine1177 phosphorylation differed between magnitudes of shear stress. It is plausible this is due to interactions with other modulators of NOS such as Threonine 495 which has been shown to coordinate eNOS activity with Serine1177 [66-69]; however, further studies are required. The observed dose-response of RBC-NOS is consistent with the effects of shear stress on RBC in vivo. Further, it was confirmed that L-NAME inhibits shear-mediated increase in RBC-NOS phosphorylation.

Author Contributions: M.J.S., S.S., and J.T.H. contributed to the conception and design of the study. M.J.S., S.S. provided reagents for conduction of the study. J.T.H. and L.K. contributed to data acquisition. J.T.H. conducted data analysis, while all authors contributed to the interpretation of the data. J.T.H. drafted the article, while all authors contributed to critical revision. All authors gave final approval and ensure the accuracy and integrity of the work. All authors have read and agreed to the published version of the manuscript.

Funding: This work was supported by the Griffith Graduate Research School of Griffith University.

Institutional Review Board Statement: The study was conducted according to the guidelines of the Declaration of Helsinki, and approved by the Human Research Ethics Committee of GRIFFITH UNIVERSITY (Protocol code: 2016/272; Date of approval: 30 September 2016).

Informed Consent Statement: Informed consent was obtained from all subjects involved in the study.

Data Availability Statement: The data that support the findings of this study are available from the corresponding author, J.T.H., upon reasonable request.

Conflicts of Interest: The authors declare no conflict of interest.

\section{References}

1. Gow, A.J.; Ischiropoulos, H. Nitric oxide chemistry and cellular signaling. J. Cell Physiol. 2001, 187, 277-282. [CrossRef] [PubMed]

2. Owusu, B.Y.; Stapley, R.; Patel, R.P. Nitric oxide formation versus scavenging: The red blood cell balancing act. J. Physiol. 2012, 590, 4993-5000. [CrossRef] [PubMed]

3. Eligini, S.; Porro, B.; Lualdi, A.; Squellerio, I.; Veglia, F.; Chiorino, E.; Crisci, M.; Garlaschè, A.; Giovannardi, M.; Werba, J.P.; et al. Nitric oxide synthetic pathway in red blood cells is impaired in coronary artery disease. PLoS ONE 2013, 8, e66945. [CrossRef] [PubMed]

4. Forstermann, U.; Sessa, W.C. Nitric oxide synthases: Regulation and function. Eur. Heart J. 2012, 33, 829-837. [CrossRef] [PubMed]

5. Tousoulis, D.; Kampoli, A.M.; Tentolouris, C.; Papageorgiou, N.; Stefanadis, C. The role of nitric oxide on endothelial function. Curr. Vasc. Pharmacol. 2012, 10, 4-18. [CrossRef] [PubMed]

6. Kleinbongard, P.; Schulz, R.; Rassaf, T.; Lauer, T.; Dejam, A.; Jax, T.; Kumara, I.; Gharini, P.; Kabanova, S.; Ozüyaman, B.; et al. Red blood cells express a functional endothelial nitric oxide synthase. Blood 2006, 107, 2943-2951. [CrossRef]

7. Grau, M.; Pauly, S.; Ali, J.; Walpurgis, K.; Thevis, M.; Bloch, W.; Suhr, F. RBC-NOS-dependent S-nitrosylation of cytoskeletal proteins improves RBC deformability. PLoS ONE 2013, 8, e56759. [CrossRef]

8. Walder, J.A.; Chatterjee, R.; Steck, T.L.; Low, P.S.; Musso, G.F.; Kaiser, E.T.; Rogers, P.H.; Arnone, A. The interaction of hemoglobin with the cytoplasmic domain of band 3 of the human erythrocyte membrane. J. Biol. Chem. 1984, 259, 10238-10246. [CrossRef]

9. Jia, L.; Bonaventura, C.; Bonaventura, J.; Stamler, J.S. S-nitrosohaemoglobin: A dynamic activity of blood involved in vascular control. Nature 1996, 380, 221-226. [CrossRef]

10. Stamler, J.S.; Jia, L.; Eu, J.P.; McMahon, T.J.; Demchenko, I.T.; Bonaventura, J.; Gernert, K.; Piantadosi, C.A. Blood flow regulation by S-nitrosohemoglobin in the physiological oxygen gradient. Science 1997, 276, 2034-2037. [CrossRef]

11. Pawloski, J.R.; Hess, D.T.; Stamler, J.S. Export by red blood cells of nitric oxide bioactivity. Nature 2001, 409, 622-626. [CrossRef]

12. Wennmalm, A.; Benthin, G.; Petersson, A.S. Dependence of the metabolism of nitric oxide (NO) in healthy human whole blood on the oxygenation of its red cell haemoglobin. Br. J. Pharmacol. 1992, 106, 507-508. [CrossRef] 
13. Ignarro, L.J.; Fukuto, J.M.; Griscavage, J.M.; Rogers, N.E.; Byrns, R.E. Oxidation of nitric oxide in aqueous solution to nitrite but not nitrate: Comparison with enzymatically formed nitric oxide from L-arginine. Proc. Natl. Acad. Sci. USA 1993, 90, 8103-8107. [CrossRef] [PubMed]

14. Eich, R.F.; Li, T.; Lemon, D.D.; Doherty, D.H.; Curry, S.R.; Aitken, J.F.; Mathews, A.J.; Johnson, K.A.; Smith, R.D.; Phillips, G.N., Jr.; et al. Mechanism of NO-induced oxidation of myoglobin and hemoglobin. Biochemistry 1996, 35, 6976-6983. [CrossRef]

15. Vitturi, D.A.; Teng, X.; Toledo, J.C.; Matalon, S.; Lancaster, J.R., Jr.; Patel, R.P. Regulation of nitrite transport in red blood cells by hemoglobin oxygen fractional saturation. Am. J. Physiol. Heart Circ. Physiol. 2009, 296, H1398-H1407. [CrossRef]

16. Grau, M.; Mozar, A.; Charlot, K.; Lamarre, Y.; Weyel, L.; Suhr, F.; Collins, B.; Jumet, S.; Hardy-Dessources, M.D.; Romana, M.; et al. High red blood cell nitric oxide synthase activation is not associated with improved vascular function and red blood cell deformability in sickle cell anaemia. Br. J. Haematol. 2015, 168, 728-736. [CrossRef]

17. Nader, E.; Grau, M.; Fort, R.; Collins, B.; Cannas, G.; Gauthier, A.; Walpurgis, K.; Martin, C.; Bloch, W.; Poutrel, S.; et al. Hydroxyurea therapy modulates sickle cell anemia red blood cell physiology: Impact on RBC deformability, oxidative stress, nitrite levels and nitric oxide synthase signalling pathway. Nitric Oxide 2018, 81, 28-35. [CrossRef]

18. Naumann, H.N.; Diggs, L.W.; Barreras, L.; Williams, B.J. Plasma hemoglobin and hemoglobin fractions in sickle cell crisis. Am. J. Clin. Pathol. 1971, 56, 137-147. [CrossRef]

19. Moncada, S.; Higgs, E.A. Nitric oxide and the vascular endothelium. Handb. Exp. Pharmacol. 2006, 176 Pt 1, $213-254$.

20. Ongini, E.; Impagnatiello, F.; Bonazzi, A.; Guzzetta, M.; Govoni, M.; Monopoli, A.; Del Soldato, P.; Ignarro, L.J. Nitric oxide (NO)-releasing statin derivatives, a class of drugs showing enhanced antiproliferative and antiinflammatory properties. Proc. Natl. Acad. Sci. USA 2004, 101, 8497-8502. [CrossRef]

21. Pacher, P.; Beckman, J.S.; Liaudet, L. Nitric oxide and peroxynitrite in health and disease. Physiol. Rev. 2007, 87, 315-424. [CrossRef] [PubMed]

22. Chen, L.Y.; Mehta, J.L. Evidence for the presence of L-arginine-nitric oxide pathway in human red blood cells: Relevance in the effects of red blood cells on platelet function. J. Cardiovasc. Pharmacol. 1998, 32, 57-61. [CrossRef] [PubMed]

23. Ulker, P.; Gunduz, F.; Meiselman, H.J.; Baskurt, O.K. Nitric oxide generated by red blood cells following exposure to shear stress dilates isolated small mesenteric arteries under hypoxic conditions. Clin. Hemorheol. Microcirc. 2013, 54, 357-369. [CrossRef] [PubMed]

24. Bohmer, A.; Beckmann, B.; Sandmann, J.; Tsikas, D. Doubts concerning functional endothelial nitric oxide synthase in human erythrocytes. Blood 2012, 119, 1322-1323. [CrossRef] [PubMed]

25. Ulker, P.; Yaras, N.; Yalcin, O.; Celik-Ozenci, C.; Johnson, P.C.; Meiselman, H.J.; Baskurt, O.K. Shear stress activation of nitric oxide synthase and increased nitric oxide levels in human red blood cells. Nitric Oxide 2011, 24, 184-191. [CrossRef]

26. Cortese-Krott, M.M.; Rodriguez-Mateos, A.; Sansone, R.; Kuhnle, G.G.; Thasian-Sivarajah, S.; Krenz, T.; Horn, P.; Krisp, C.; Wolters, D.; Heiss, C.; et al. Human red blood cells at work: Identification and visualization of erythrocytic eNOS activity in health and disease. Blood 2012, 120, 4229-4237. [CrossRef]

27. Boo, Y.C.; Sorescu, G.; Boyd, N.; Shiojima, I.; Walsh, K.; Du, J.; Jo, H. Shear stress stimulates phosphorylation of endothelial nitric-oxide synthase at Ser1179 by Akt-independent mechanisms: Role of protein kinase A. J. Biol. Chem. 2002, 277, 3388-3396. [CrossRef]

28. Michel, T.; Feron, O. Nitric oxide synthases: Which, where, how, and why? J. Clin. Investig. 1997, 100, 2146-2152. [CrossRef]

29. Garcin, E.D.; Bruns, C.M.; Lloyd, S.J.; Hosfield, D.J.; Tiso, M.; Gachhui, R.; Stuehr, D.J.; Tainer, J.A.; Getzoff, E.D. Structural basis for isozyme-specific regulation of electron transfer in nitric-oxide synthase. J. Biol. Chem. 2004, 279, 37918-37927. [CrossRef]

30. Burgering, B.M.; Coffer, P.J. Protein kinase B (c-Akt) in phosphatidylinositol-3-OH kinase signal transduction. Nature 1995, 376, 599-602. [CrossRef]

31. Suhr, F.; Brenig, J.; Muller, R.; Behrens, H.; Bloch, W.; Grau, M. Moderate exercise promotes human RBC-NOS activity, NO production and deformability through Akt kinase pathway. PLoS ONE 2012, 7, e45982. [CrossRef] [PubMed]

32. Stimpel, M.; Neyses, L.; Locher, R.; Groth, H.; Vetter, W. Human red blood cells-an ideal model system for the action of calcium agonists and antagonists. J. Hypertens. Suppl. 1984, 2, S577-S580. [PubMed]

33. Lin, M.S.; Huang, C.S.; Leen, D.Y. Lack of effects of calcium antagonists on red blood cell deformability in hypertension. Int. J. Clin. Pharmacol. Ther. Toxicol. 1988, 26, 585-587. [PubMed]

34. Koutsiaris, A.G.; Tachmitzi, S.V.; Batis, N. Wall shear stress quantification in the human conjunctival pre-capillary arterioles in vivo. Microvasc. Res. 2013, 85, 34-39. [CrossRef]

35. Papaioannou, T.G.; Stefanadis, C. Vascular wall shear stress: Basic principles and methods. Hellenic. J. Cardiol. $2005,46,9-15$.

36. Horobin, J.T.; Simmonds, M.J.; Nandakumar, D.; Gregory, S.D.; Tansley, G.; Pauls, J.P.; Girnghuber, A.; Balletti, N.; Fraser, J.F. Speed Modulation of the HeartWare HVAD to Assess In Vitro Hemocompatibility of Pulsatile and Continuous Flow Regimes in a Rotary Blood Pump. Artif. Organs 2018, 42, 879-890. [CrossRef]

37. Grau, M.; Cremer, J.M.; Schmeichel, S.; Kunkel, M.; Bloch, W. Comparisons of Blood Parameters, Red Blood Cell Deformability and Circulating Nitric Oxide Between Males and Females Considering Hormonal Contraception: A Longitudinal Gender Study. Front. Physiol. 2018, 9, 1835. [CrossRef]

38. Horobin, J.T.; Sabapathy, S.; Simmonds, M.J. Repetitive Supra-Physiological Shear Stress Impairs Red Blood Cell Deformability and Induces Hemolysis. Artif. Organs 2017, 41, 1017-1025. [CrossRef] 
39. Hardeman, M.R.; Goedhart, P.; Breederveld, D. Laser diffraction ellipsometry of erythrocytes under controlled shear stress using a rotational viscosimeter. Clin. Chim. Acta 1987, 165, 227-234. [CrossRef]

40. Fischer, U.M.; Schindler, R.; Brixius, K.; Mehlhorn, U.; Bloch, W. Extracorporeal circulation activates endothelial nitric oxide synthase in erythrocytes. Ann. Thorac. Surg. 2007, 84, 2000-2003. [CrossRef]

41. Curran, R.C.; Gregory, J. The unmasking of antigens in paraffin sections of tissue by trypsin. Experientia 1977, 33, 1400-1401. [CrossRef] [PubMed]

42. Bogen, S.A.; Vani, K.; Sompuram, S.R. Molecular mechanisms of antigen retrieval: Antigen retrieval reverses steric interference caused by formalin-induced cross-links. Biotech. Histochem. 2009, 84, 207-215. [CrossRef] [PubMed]

43. Polak, J.M.; van Noorden, S. Introduction to Immunocytochemistry, 2nd ed.; Springer: Oxford, UK, 1997.

44. Kuck, L.; Grau, M.; Bloch, W.; Simmonds, M.J. Shear Stress Ameliorates Superoxide Impairment to Erythrocyte Deformability with Concurrent Nitric Oxide Synthase Activation. Front. Physiol. 2019, 10, 36. [CrossRef] [PubMed]

45. Dimmeler, S.; Fleming, I.; Fisslthaler, B.; Hermann, C.; Busse, R.; Zeiher, A.M. Activation of nitric oxide synthase in endothelial cells by Akt-dependent phosphorylation. Nature 1999, 399, 601-605. [CrossRef] [PubMed]

46. Koo, A.; Nordsletten, D.; Umeton, R.; Yankama, B.; Ayyadurai, S.; Garcia-Cardena, G.; Dewey, C.F., Jr. In silico modeling of shear-stress-induced nitric oxide production in endothelial cells through systems biology. Biophys. J. 2013, 104, 2295-2306. [CrossRef]

47. Shin, S.; Mohan, S.; Fung, H.L. Intracellular L-arginine concentration does not determine NO production in endothelial cells: Implications on the "L-arginine paradox". Biochem. Biophys. Res. Commun. 2011, 414, 660-663. [CrossRef]

48. Omodeo-Sale, F.; Cortelezzi, L.; Vommaro, Z.; Scaccabarozzi, D.; Dondorp, A.M. Dysregulation of L-arginine metabolism and bioavailability associated to free plasma heme. Am. J. Physiol. Cell. Physiol. 2010, 299, C148-C154. [CrossRef]

49. Fujiwara, T.; Kanazawa, S.; Ichibori, R.; Tanigawa, T.; Magome, T.; Shingaki, K.; Miyata, S.; Tohyama, M.; Hosokawa, K. L-arginine stimulates fibroblast proliferation through the GPRC6A-ERK1/2 and PI3K/Akt pathway. PLoS ONE 2014, 9, e92168. [CrossRef]

50. Xiao, H.; Zeng, L.; Shao, F.; Huang, B.; Wu, M.; Tan, B.; Yin, Y. The role of nitric oxide pathway in arginine transport and growth of IPEC-1 cells. Oncotarget 2017, 8, 29976-29983. [CrossRef]

51. Kopincova, J.; Puzserova, A.; Bernatova, I. Biochemical aspects of nitric oxide synthase feedback regulation by nitric oxide. Interdis. Toxicol. 2011, 4, 63-68. [CrossRef]

52. Ravi, K.; Brennan, L.A.; Levic, S.; Ross, P.A.; Black, S.M. S-nitrosylation of endothelial nitric oxide synthase is associated with monomerization and decreased enzyme activity. Proc. Natl. Acad. Sci. USA 2004, 101, 2619-2624. [CrossRef]

53. Huang, B.; Chen, S.C.; Wang, D.L. Shear flow increases S-nitrosylation of proteins in endothelial cells. Cardiovasc. Res. 2009, 83, 536-546. [CrossRef] [PubMed]

54. Ischiropoulos, H. Biological tyrosine nitration: A pathophysiological function of nitric oxide and reactive oxygen species. Arch. Biochem. Biophys. 1998, 356, 1-11. [CrossRef] [PubMed]

55. Van der Vliet, A.; Hoen, P.A.; Wong, P.S.; Bast, A.; Cross, C.E. Formation of S-nitrosothiols via direct nucleophilic nitrosation of thiols by peroxynitrite with elimination of hydrogen peroxide. J. Biol. Chem. 1998, 273, 30255-30262. [CrossRef] [PubMed]

56. O'Donnell, V.B.; Eiserich, J.P.; Chumley, P.H.; Jablonsky, M.J.; Krishna, N.R.; Kirk, M.; Barnes, S.; Darley-Usmar, V.M.; Freeman, B.A. Nitration of unsaturated fatty acids by nitric oxide-derived reactive nitrogen species peroxynitrite, nitrous acid, nitrogen dioxide, and nitronium ion. Chem. Res. Toxicol. 1999, 12, 83-92. [CrossRef]

57. Horobin, J.T.; Watanabe, N.; Hakozaki, M.; Sabapathy, S.; Simmonds, M.J. Shear-stress mediated nitric oxide production within red blood cells: A dose-response. Clin. Hemorheol. Microcirc. 2019, 71, 203-214. [CrossRef]

58. Secomb, T.W. Theoretical models for regulation of blood flow. Microcirculation 2008, 15, 765-775. [CrossRef]

59. Duling, B.R.; Berne, R.M. Longitudinal gradients in periarteriolar oxygen tension. A possible mechanism for the participation of oxygen in local regulation of blood flow. Circ. Res. 1970, 27, 669-678. [CrossRef]

60. Popel, A.S.; Pittman, R.N.; Ellsworth, M.L.; Weerappuli, D.P. Measurements of oxygen flux from arterioles imply high permeability of perfused tissue to oxygen. Adv. Exp. Med. Biol. 1989, 248, 215-225.

61. Torres Filho, I.P.; Kerger, H.; Intaglietta, M. pO2 measurements in arteriolar networks. Microvasc. Res. 1996, 51, 202-212. [CrossRef]

62. Bauer, P.M.; Fulton, D.; Boo, Y.C.; Sorescu, G.P.; Kemp, B.E.; Jo, H.; Sessa, W.C. Compensatory phosphorylation and protein-protein interactions revealed by loss of function and gain of function mutants of multiple serine phosphorylation sites in endothelial nitric-oxide synthase. J. Biol. Chem. 2003, 278, 14841-14849. [CrossRef] [PubMed]

63. Dudzinski, D.M.; Michel, T. Life history of eNOS: Partners and pathways. Cardiovasc. Res. 2007, 75, 247-260. [CrossRef] [PubMed]

64. Michell, B.J.; Harris, M.B.; Chen, Z.P.; Ju, H.; Venema, V.J.; Blackstone, M.A.; Huang, W.; Venema, R.C.; Kemp, B.E. Identification of regulatory sites of phosphorylation of the bovine endothelial nitric-oxide synthase at serine 617 and serine 635 . J. Biol. Chem. 2002, 277, 42344-42351. [CrossRef] [PubMed]

65. Alderton, W.K.; Cooper, C.E.; Knowles, R.G. Nitric oxide synthases: Structure, function and inhibition. Biochem. J. 2001, 357, 593-615. [CrossRef]

66. Fleming, I.; Fisslthaler, B.; Dimmeler, S.; Kemp, B.E.; Busse, R. Phosphorylation of Thr regulates Ca(2+)/calmodulin-dependent endothelial nitric oxide synthase activity. Circ. Res. 2001, 88, E68-E75. [CrossRef]

67. Harris, M.B.; Ju, H.; Venema, V.J.; Liang, H.; Zou, R.; Michell, B.J.; Chen, Z.P.; Kemp, B.E.; Venema, R.C. Reciprocal phosphorylation and regulation of endothelial nitric-oxide synthase in response to bradykinin stimulation. J. Biol. Chem. 2001, 276, 16587-16591. [CrossRef] 
68. Michell, B.J.; Chen, Z.; Tiganis, T.; Stapleton, D.; Katsis, F.; Power, D.A.; Sim, A.T.; Kemp, B.E. Coordinated control of endothelial nitric-oxide synthase phosphorylation by protein kinase $C$ and the cAMP-dependent protein kinase. J. Biol. Chem. 2001, 276, 17625-17628. [CrossRef]

69. Thomas, S.R.; Chen, K.; Keaney, J.F., Jr. Hydrogen peroxide activates endothelial nitric-oxide synthase through coordinated phosphorylation and dephosphorylation via a phosphoinositide 3-kinase-dependent signaling pathway. J. Biol. Chem. 2002, 277, 6017-6024. [CrossRef] 